\title{
CHARTER AUTHENTICATED ANTI-THEFT SECURE MOTOR SYSTEM
}

\author{
Sharmila $P^{l}$, Brindha Dev ${ }^{l}$, Akshaya 1, Dhanvarsha $D^{l}$, Pavai $A^{l}$ \\ ${ }^{1}$ Department of Information Technology, Sri Sairam Institute Of Technology, Chennai.
}

\begin{abstract}
The prominent mode of transportation being used by the public is roadways. Increased usage of roadways may lead to many accidents and thefts. The major reason is violation of rules drafted for driving and causing accidents mainly by the youngsters who does not have a proper knowledge and license. So this proposed system has some restrictions to follow the rules drafted for driving and for higher safe and security, the License is scanned by means of NFC tag. When it is read by the NFC reader, Node MCU provides two-way authentication facility by sending an SMS to both the owner for authorization and the authorized current user would be able to control our vehicle by means of switching on and off the engine. The owner authorizes the user for a particular time period by using real time clock module. Without authorizing the license, the engine cannot have turned on. So, in this case license become mandatory to drive the vehicle. The features of the application to control the vehicle through the attached device. This will help a person to control the vehicle from anywhere. If a robber tries to snip the vehicle, immediately the Micro-Electromechanical System sends a signal to the controller and will be notified by a text message. Any violation to unlock the vehicle, emergency alert will send to owner as well as the current user and alarm blows out to seek the attention. This device can setup both in two-wheeler and four-wheeler.
\end{abstract}

\section{Introduction}

User friendly and safety are important in today's world. Nowa-days automobile burglary cases and road accidents are increasing day by day. Securing the vehicles are the prime concern. Initially, the License is scanned by means of NFC tag and secondly an android application which sends SMS to both the owner for authorization and the current user would be able to control our vehicle by means of switching on and off the engine. Without authorizing the license, the engine cannot have turned on. So, in this case license become mandatory to drive the vehicle. Once the license is Scanned the application will send the message to the owner, with the help of this system a person can find the vehicle's current location, stop the vehicle and raise an alarm. If a suspicious person tries to snip or ride the vehicle will alert an owner via text messages. Any violation to unlock the vehicle, emergency alert will send to owner as well as the current user and alarm blows out to seek the attention. User Authentication plays an important role in Security Systems, authentication allows a person to access the system based on the identity verification.

In this proposed motor System, two type of Authentication is used. Initially, by the owner for authorizing the user and the authorized user for further access of the vehicle. This provides higher safety of our vehicle that being theft. AntiTheft Security is a complete and intuitive application. Antitheft Security has many features to increase chances to not only recover our vehicle but also identify the theft.

Corrosponding author:sharmila.it@sairamit.edu.in

\section{Literature Survey}

An Anti-Theft System for Vehicles using Fingerprint Sensor for preventing the vehicle from probable theft. This vehicle tracking system is distributed, to track the position of vehicle and provide security to vehicle ${ }^{[1]}$. Anti-Theft and security System for two Wheelers uses GSM or GPS to find the current location of the vehicle. The direction and the distance are transmitted to GSM through Microcontroller An AntiTheft Security System for Vehicles gives an alarm when someone tries to access the vehicle. This is a security technique for our vehicle which avoids trespassers to mishandle it ${ }^{[3][4]}$.

\subsection{Existing System}

Vehicle tracking system is becoming more popular because the count of vehicle theft is increasing enormously, Vehicle theft is happening on parking and sometimes driving in unknown places. The existing system contains embedded device integrated with global system for mobile (GSM) and global positioning system (GPS) along with a microcontroller installed to the vehicle. The use of GSM and GPS technologies allows the user to track the vehicle location details then and there. Moreover, fingerprint verification is used in the implemented system to ensure the correct person is driving the vehicles. But the use of sensor is difficult in Emergency situation and there may be a possibility of locking the vehicle. This issue is resolved in our proposed system. Few of the important features supported by our system are alerting owner by SMS about the theft attempt, tracking the location of vehicle using GPS technology. Our system has further enhancement of controlling the vehicle remotely by SMS and authorizing the user by the owner for providing higher security of the vehicle. ${ }^{[7][8]}$ 


\section{Proposed System}

Road accident is one of the major problem in current situation. In order to bring out the safer driving, this following system is proposed. It consists of three modules. First, the user's license is scanned by means of NFC tag and when it is read, the microcontroller sends a message to the owner for authorization. The authorized user can access the vehicle for an authorized period of time. ${ }^{[1]}$

Second, if the license is lost and finds any illegal activity, the user is allowed to lock the vehicle by using mobile application to prevent from theft. ${ }^{[2]}$

Third, if anyone tries to unlock the vehicle, the microelectromechanical system sends a signal to microcontroller, immediately an emergency alert message sends to both the owner and the current user, simultaneously alarm blows out to have a surrounding attention.

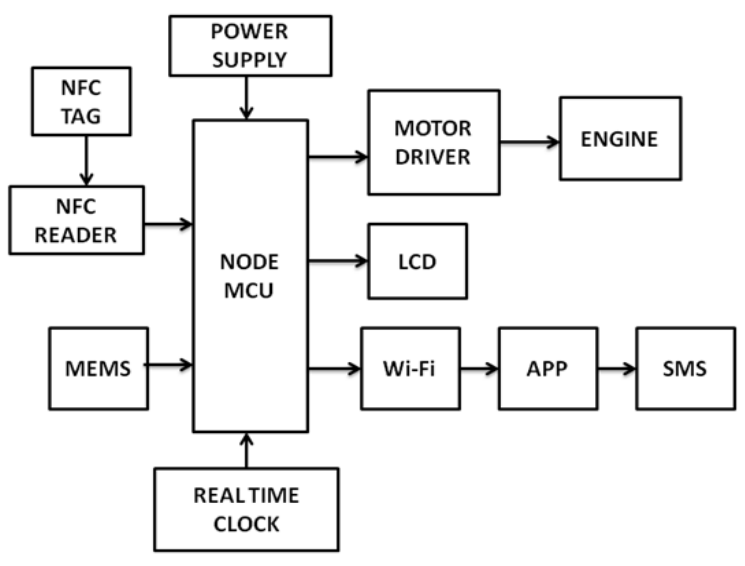

Fig.1. Data flow diagram represents the flow of data and control in the system

\subsection{Block diagram description}

\subsubsection{Power supply}

The supply of 5 volts is given as an input to the micro controller.

\subsubsection{NFC Tag and Reader}

A near field communication tag (NFC) is a small microchip in which it stores the user license information and that can be read by the NFC reader. The stored information can be used for authorization. With NFC capabilities, the tag has the ability to send data to other system. This module can operate without power supply.

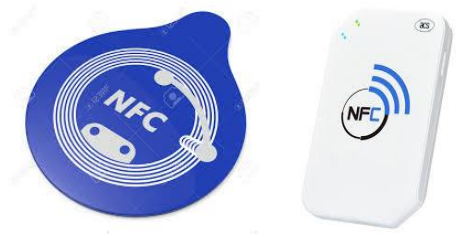

Fig.2. Near Field Communication Tag

\subsubsection{Node MCU}

Node MCU (Node Microcontroller) is an open source firmware to develop IOT applications. It is used in the proposed system to manage and control the entire system.

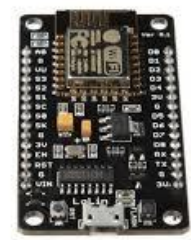

Fig.3.. Node MCU

\subsubsection{Micro-Electromechanical System}

A MEMS is a small device that has both electronic and mechanical components, it is used to sense, control and actuate and generate. It response the slight changes that made in the vehicle and transmit the signal to the microcontroller. Then that signal can be changed to create a stable output signal and it is transmitted to the microcontroller for further actions ${ }^{[5]}$. This result in sending the emergency alert message to the user and the owner.

\subsubsection{Motor Driver}

Motor Driver is an amplifier which accept the signal from the controller (Node MCU) and helps to drive the motor depending upon the condition given by the current user through mobile application. Depending upon the signal given by the microcontroller, a motor driver controls the speed of the vehicle and switching ON/OFF of an engine motor ${ }^{[13]}$.

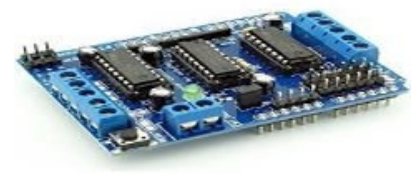

Fig.4.. Motor Driver 


\subsubsection{Liquid Crystal Display(LCD)}

LCD used to display the current status of the system, it uses active matrix display for more clarity ${ }^{[14] . ~ I t ~}$ works on the principle of blocking light rather than emitting light.

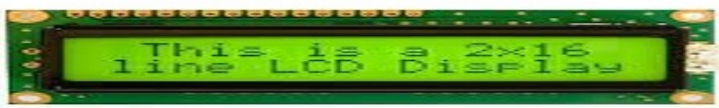

Fig.5. Liquid Crystal Display

\subsubsection{Mobile application}

For increasing accessibility, the entire system can be connected to the mobile application. Through mobile application, with the help of Internet, one can control the system by clicking on the respective function. The major advantage of having a mobile application is faster to access and authorization is done by the owner through this application.

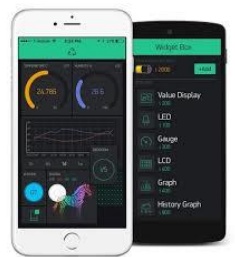

Fig.6. Mobile Application

\subsubsection{Real time clock(RTC)}

RTC is used to provide an authorized access for a particular time. Often this device used in personal computers, servers and embedded system. This module takes a low power consumption for performing a time-critical tasks ${ }^{[3]}$.

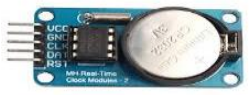

Fig.7. Real time clock

\section{Working}

The proposed system "LICENSE AUTHENTICATED MOTOR SYSTEM IN ROADWAYS" have developed with the help of NFC tag, NFC reader and a Node MCU. In this technique the scanning of license is introduced. The information of user's license is stored in NFC tag. The user can access the motor with the help of this tag. Once the tag is read by the reader, the SMS sends to the owner with the help of GSM module which was controlled by Node MCU. The owner authorizes the user for a particular time period by using real time clock module ${ }^{[6] \text {. The }}$ authorized user can access the motor for a specified time. Once the time expires, automatically the engine cut-off. For further continuation of driving, the user should repeat the process again. When the tag is lost, the owner may not aware of authorizing who is going to drive the vehicle. In this circumstance, the user who lost his license can lock the engine through SMS. When the thief tries to unlock the vehicle, the Micro-Electromechanical System sends a signal to the controller. As soon as the alert SMS will send to owner as well as the current user. Simultaneously, the alarm blows out to seek the attention of surrounding people. This device can setup both in twowheeler and four-wheeler ${ }^{[4]}$.

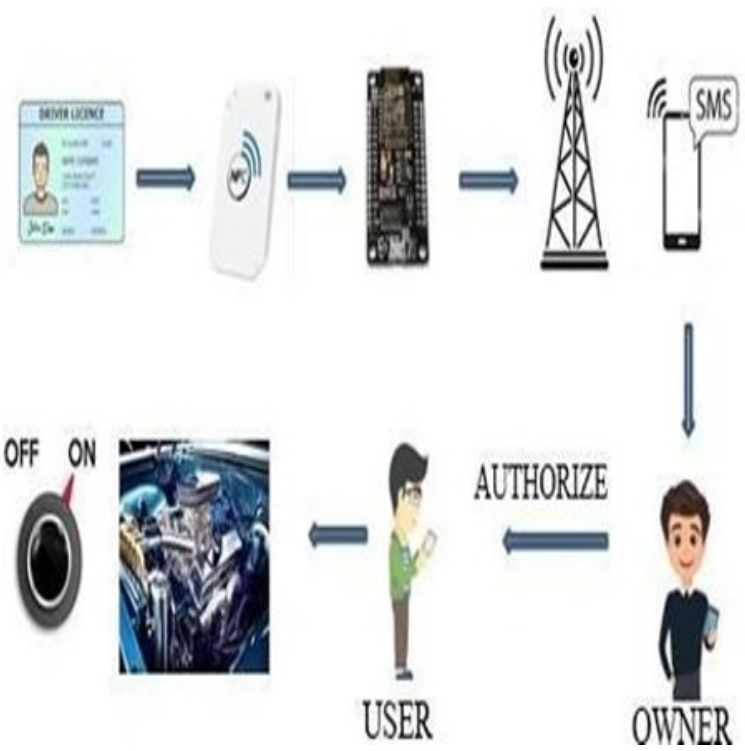

Fig.8. Authentication of an owner and access of an authorized user

Authentication of a Motor System: To make a license to be a mandatory one, we have proposed a system in which license information are stored by means of NFC tag ${ }^{[10]}$. Once the tag read by the NFC Reader, the information is transformed to the microcontroller (Node MCU). It will send a SMS to the owner to authorize the user for a particular time period. The authorized user is allowed to use the motor for a given period. If the requested user is not authorized by the owner, then the user access is denied ${ }^{[15]}$. Locking The System by Using Mobile Application: In case the stolen license of the user is used to operate the vehicle, the microcontroller will send the alert message to the owner. Without the knowledge of the theft, the owner authorizes the user. But the user can lock the vehicle by using mobile application ${ }^{[11]}$. 


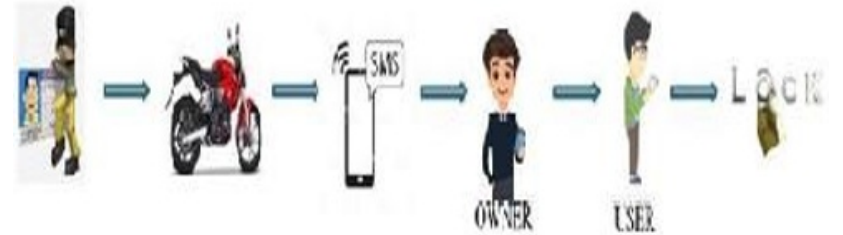

Fig.9. Locking the entire system by using mobile application

Security Alert System: If there is any illegal activity like vehicle theft, the alert message will send to the owner as well as the current user. Simultaneously, the alarm blows out to seek the surrounding attention.
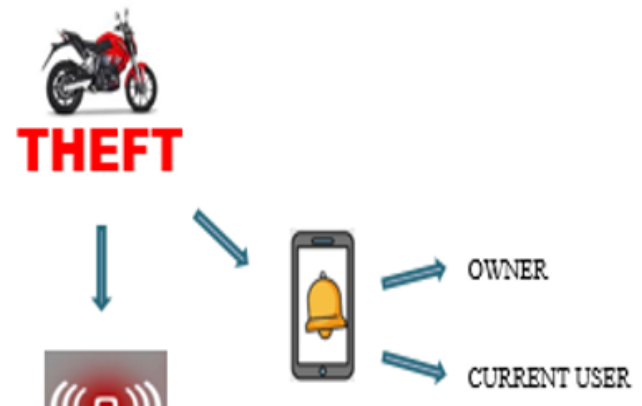

Fig.10. Emergency alert to have higher security

\section{Experimental Setup and Result}

This system has developed with the help of NFC tag, NFC reader and a Node MCU. In this technique the scanning of license is introduced. The information of user's license is stored in NFC tag. The user can access the motor with the help of this tag. Once the tag is read by the reader, the SMS sends to the owner with the help of GSM module which was controlled by Node MCU.

The owner authorizes the user for a particular time period by using real time clock module. The authorized user can access the motor for a specified time. Once the time expires, automatically the engine cut-off. For further continuation of driving, the user should repeat the process again. When the tag is lost, the owner may not aware of authorizing who is going to drive the vehicle. In this circumstance, the user who lost his license can lock the engine through SMS.

When the thief tries to unlock the vehicle, the MicroElectromechanical System sends a signal to the controller. As soon as the alert SMS will send to owner as well as the current user. Simultaneously, the alarm blows out to seek the attention of surrounding people. This device can setup both in two-wheeler and four-wheeler.

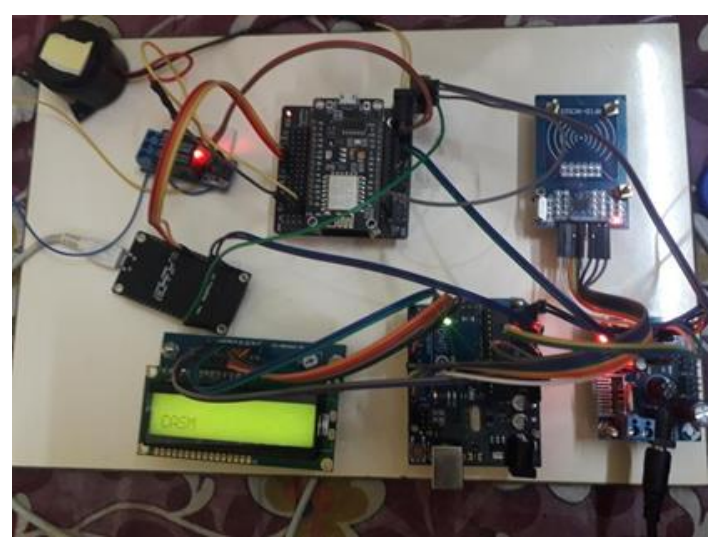

Fig.11. Hardware set up

Fig.12. shows the alert message sent to the user from

Charter Authentication System.

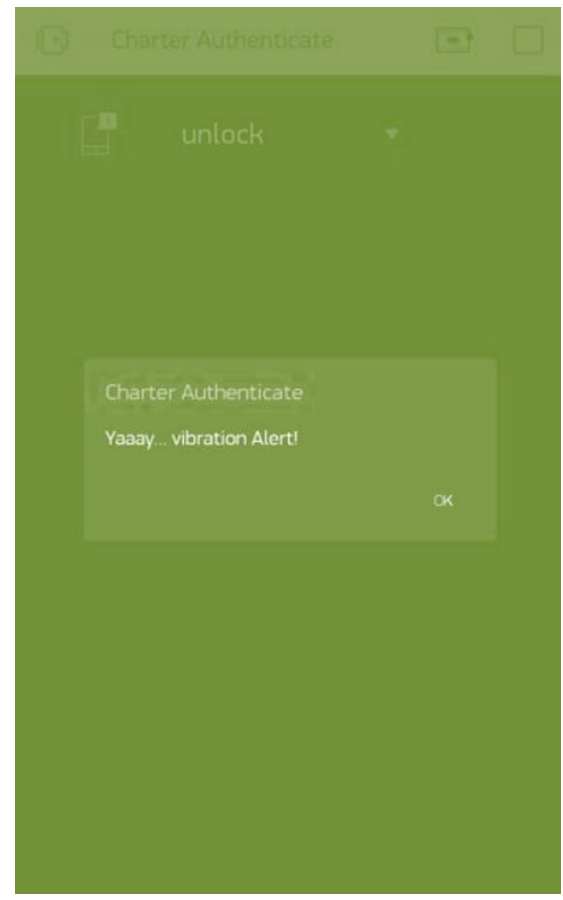

Fig.12. Application showing alert message.

\section{Performance Evaluation}

The reliability test result shows the system performance was good when the distance is minimum, to turn engine on/off for the distance of 1 meter the system takes 0.5 seconds, for maximum of 20-meter distance the system takes 4 seconds. License scanning message to reach the users application takes 
1 second, for maximum of 20-meter distance the system takes 5 seconds.

\begin{tabular}{|l|l|l|l|}
\hline ACT & $\begin{array}{l}\text { Distance } \\
\text { in meter }\end{array}$ & $\begin{array}{l}\text { Time in } \\
\text { seconds }\end{array}$ & Response \\
\hline MOTOR ON /OFF & $1-4$ & 0.5 & Good \\
\hline MOTOR ON /OFF & $5-10$ & 1 & Good \\
\hline MOTORON /OFF & $11-15$ & 2 & Good \\
\hline MOTOR ON /OFF & $15-20$ & 4 & Good \\
\hline MOTOR ON /OFF & $21-25$ & - & $\begin{array}{l}\text { Connection } \\
\text { Lost }\end{array}$ \\
\hline Licence Scaning message & $1-4$ & 1 & Good \\
\hline Licence Scaning message & $5-10$ & 1.5 & Good \\
\hline Licence Scaning message & $11-15$ & 3 & Good \\
\hline Licence Scaning message & $15-20$ & 5 & Good \\
\hline Licence Scaning message & $21-25$ & - & $\begin{array}{l}\text { Connection } \\
\text { Lost }\end{array}$ \\
\hline
\end{tabular}

Table1.System performance

\section{Conclusion and Future work}

In this work provides a safety and security mechanisms for motor vehicles. This system consists of a license scanner methodology as well as authentication methodology. This device can be implemented in all motor vehicle to increase the security system and also the safety of the riders, and this system will effectively have applied in the future and also the result will be better. In this method, License plays a key role in accessing the vehicle ${ }^{[9]}$. Thus it reduces a rate of accidents in day-to-day life. Furthermore, the proposed method has a strong advantage in that it provides two-way authentication system. Initially, by the owner for authorizing the requested user. Secondly, the authorized user can unlock the vehicle by using mobile application in order to access the vehicle. In case of theft of license, the authorized user can lock the motor in a fraction of second by using mobile application. This provides more security to the vehicle and prevent from illegal activities. In future, the motor vehicle manufacturing industry can inbuilt this device in their production in order to provide higher safe and security for both the human and the vehicle. Unlike motor vehicle industry, we can also implement for four wheeler and heavy vehicle to provide safe environment for the users.

\section{References}

1.JoelSachin,Kiran Rana Gill,Anti-Theft System For Vehicles Using Fingerprint sensor,IJSER,7,14361441(2016).
2. Shanmuganathan J , B.C.Kavitha, Tracking and Theft Prevention System for Two Wheeler Using Android,IJETT,21,355-359(2015).

3. Samir Rana, Ritu Mewari, LataNautiyal ,Anti-theft Security System for Vehicles,IJET,7,42-46(2018).

4. Prakash Kumar, Pradeep Kumar, Arduino Based Wireless Intrusion Detection Using IR Sensor and GSM,IJCSMC,2,417-424(2013).

5.Jayanta Kumar Pandey, R.N. Das choudhary,Embedded Automobile Engine locking System, using GSM technology,IJICA,1,154-158(2011).

6. Pritpal Singh, Tanjot Sethi, Sujit Kumar Pattanayak ,a smart anti theft system for vehicle security,IJMMM, 3, 2243(2015).

7. Nurul Hutha.S and ArunKumar.B, Vehicle Monitoring and Theft Prevention System Using ARM Cortex, IJSETR, 2, 992-997(2013).

8. Pritpal Singh, Tanjot Sethi, Bunil Kumar Balabantaray, Bibhuti Bhushan Biswal,Advanced Vehicle Security System" IEEE Xplore(2015).

9. L. K. Hema, Achal Mercy Banra, Raju Kumar and Ranu Rakesh Singh,Int. J. Chem.,An Intelligent Automobile AntiTheft System ,IJCS,14, 863-868 (2016).

10. B. R. Prudhvi and Yuvapreethi Ganesh, Gravity Lock: Next Generation Auto Theft Prevention System, International, ICAEE, 175-178 (2013).

11. S. Zhou, Q. Shan, F. Fei, W. J. Li, C. P. Kwong, C. K. Wu et al., "Gesture Recognition for Interactive Controllers using MEMS Motion Sensors", IEEE Xplore, 935- 940 (2009).

12. Geeth Jayendra, Sisil Kumarawadu and Lasantha Meegahapola ,RFID-Based Anti-theft Auto Security System with an immobilizer" ICIIS ,8 - 11 (2007).

13. Robert Bosch GmbH, 2001, "Device for protecting a motor vehicle against theft “, United States Patent 6856044 Nov 7(2001).

14. M. A. A. Khedher, Hybrid GPS-GSM localization of automobile tracking system,IJCSIT. 3, 75-85, (2011).

15. P. P. Wankhade and S. O. Dahad, ,Real time vehicle locking and tracking system using GSM and GPS technology-an anti-theft system,IJTE, 2,272-275, (2011). 